\title{
CREATIVE WORK
}

\section{Telling Stories / Empty Words Build Empty Homes}

\author{
David Roberts*
}

\begin{abstract}
This article places two texts on the pursuit of public housing in parallel. Empty Words Build Empty Homes is the script of a site-specific play that was performed with a small cast of residents at the soon-to-be demolished Haggerston West Estate in Hackney, East London on 22 September 2012. It takes architecture as storyteller, drawing on the physical structure of the estate's last standing block to determine narrative and express the position of those who have conceived, perceived and represented it. Telling Stories is a short commentary that promotes and problematises the act and ethics of sharing research publicly by critically reflecting on the production of the script and play.
\end{abstract}

\section{Telling Stories}

Thus traces of the storyteller cling to the story the way the handprints of the potter cling to the clay vessel. (Benjamin 1968: 92)

On 22 September 2012 I performed a site-specific play Empty Words Build Empty Homes at the soon-to-be demolished Haggerston West Estate in Hackney, East London as part of a free day of tours, collective discussions and performances for the local community that was open to the public. I include the script in parallel to this establishing commentary to share my clumsy words crafted by inexperienced hands alongside the premise, promise and pitfalls of performing ongoing research to others.

My thesis is a practical and theoretical research project into the pursuit of public housing, an ideal and form that is being dismantled in London, the city that pioneered its modern principles (Edwards 2011; Hodkinson and Robbins 2013; Lees et al 2013; Phillips and Erdemci 2012; Watt 2009, 2013). My research uses archival material, oral history and collaborative workshops to challenge that most common estate biography - an abrupt descent from utopian golden age to dystopian reality, presenting as a finite narrative the death of public housing (McGuirk 2012; Moss 2011). I develop practices of writing, photography and performance that enable residents to encounter, develop their own lines of enquiry and critically respond to academic debates in architectural history, critical theory and housing policy. I aim to conceptually and physically bring ideas and people together in order to reconsider their position and action, and reimagine public housing together.

\footnotetext{
* The Bartlett School of Architecture, University College London, United Kingdom david.roberts@ucl.ac.uk
} 
In my long-term engagement with the Haggerston Estate as a member of collaborative art practice Fugitive Images alongside Andrea Luka Zimmerman and Lasse Johannson, residents have generously shared their lived experiences in filmed workshops and performances. Dividing my time between residents and research material of newspaper cuttings, historical maps, surveyors' notes and political speeches, I have come to appreciate the disjuncture between lived reality and representation. Haggerston's residents share a history of resistance and resilience, fighting to improve their estate for thirty years, but their voices cannot be heard above the cacophony of journalistic clichés that inform public perspectives, correlating material deterioration of estates with social deterioration of their communities (see Hatherley 2012; Jones 2011; Slater 2013; Watt 2008). Through this, I became interested in the medium of storytelling - what the spoken tale can convey that the written article cannot.

In 1936, the same year the Haggerston Estate was rising, Walter Benjamin published an essay which described the fall of storytelling at a time when people felt unable to reflect on and articulate their experiences. Theatre-maker Mike Pearson draws strength from his words:

Yet, in the great silence which followed the Great War - silent because men returned stunned by the enormity of the first mechanical conflict - Benjamin realised that one inalienable possession had been lost, the ability to exchange experiences, to make the personal interpersonal. It was as if experience had fallen in value and the epic side of truth, wisdom, was dying out. Thus was storytelling reaching its end. It seems so familiar to us, so resonant of 'the great slackening' in contemporary society. Perhaps then the telling of stories, a reawakened interest in the direct experience of self and others, might constitute a point of resistance, a political project. As a contemporary practice, it might serve to create, challenge and change identities and orientations, personal, communal and artistic. (1995: 79)

At an early stage in my research the last standing block of the estate was earmarked for demolition. I conceived of a site-specific play advertised as a tour for Open House weekend to tell alternative stories of the estate, opening up the building and my research as a small point of resistance. Usually tours demand the positioning of an eager critic between viewer and architecture, dispensing wisdom on how they experience the building they are standing in front of. I neither wished my performance to privilege one way of seeing nor allow the audience to rush to conclusions. The play presented an opportunity to collapse critical distance and bring in different modes of reflection. I turned to ideas from teaching, theory and practice to assist me in writing a script which ties together the archival and anecdotal, political and personal, bureaucratic and emotional threads that bind it without resolution. I developed these in the company of Benjamin and the following four critical thinkers who made me think and see this material and medium anew.

In weekly group visits to buildings for The Bartlett's Architectural History MA, Adrian Forty would identify the kinds of knowledge specific to built works of architecture, interrogating buildings themselves as historical objects - what can be discovered from them, and from them alone (2013a). Forty observed that the architectural historian today prefers to talk about a drawing or photograph, text or document; and the building itself can too often recede into the distance. He explained the purpose of this knowledge to us: 'We study history to reduce anxiety in the present. We study not to tidy and neaten, but give voice to contradictory thoughts, to see patterns in their consequences' (2013b).

Architectural designer and historian Jane Rendell's praxis of site-writing explores the position of the critic 'not only in relation to art objects, architectural spaces and theoretical ideas, but also through the site of writing itself' (2010). Rendell uses writing as critical spatial prac- 
tice where spatial qualities of writing create relays between the analytic and poetic and forge new spaces of relation between people.

In Site-Specific Performance (2010), Mike Pearson encourages practical initiatives and develops theories in the conception, devising and staging of performances based on his pioneering work with Brith Gof. He uses the full volume and arc of spaces in theatrical style and dramatic form, attending to the dimensions and textures of architecture and audience by choreographing viewpoints and relationships. Particularly interesting is his abandon of fictional characters in favour of the monologue of the storyteller which, he suggests, 'exhibit[s] a different form of "dialogue": a high order of inter-textuality, of dialogue between texts. It can encompass the fragmentary, the digressive, the ambiguous, the appropriated, in juxtaposition and in contradiction' (Pearson 1995: 79).

Finally, theorist Peggy Phelan describes performance as an enactment predicated on its own disappearance. To confront the impossibility of documenting performance without fundamentally changing it, Phelan argues that critics must instead approach writing about performance as a performance itself. She calls for a 'writing toward disappearance', that does not seek to recreate the performance, but to 'restage and restate the effort to remember what is lost' (Phelan 1993: 147-8).

I borrowed ideas from these thinkers and ran with them. Like Forty, I wished to bring visitors to the estate in order keep the building and its residents in the foreground as both object and content and keep alive its historical contradictions. Like Rendell, I wished to write the site, transforming readers from passive viewers to active engagers, and to draw attention to how I, and others, have looked at the estate in our sites of writing, making tangible the changing positions we occupy in relation to it. Like Pearson, I wished to take architecture as an active element in the narrative. I explored the art of script writing, scenario and scenography in the work of others (Brecht 1957; Crouch 2007; Foster and Heighes 2011; Kaye 2000; McAuley 1999; Wrights \& Sites 2003), choosing to make explicit the 'representational apparatus'-the stage directions, set, costumes-during the performance by incorporating them into the dialogue and bringing the audience into the process. I wished to accompany it with a script, but like Phelan, I did not wish to present performance and writing as 'sibling practices, but as inextricable parts of each other' (Manis 2009: 149). With the estate's imminent demolition, this was to be an enactment where performance and building disappear. I conceived elaborate stage directions inspired by Phelan to write this disappearance. They address director, actor and reader, detailing the stage scenery, prescribing actions and imagining a restaging of the estate itself.

The play takes the estate as storyteller, drawing on its physical structure to determine the narrative. It begins with a eulogy to public housing, a rubbish chute my pulpit, and ends with a rallying cry, a balcony my rostrum. It takes place in three acts entitled 'At', 'With' and 'Within' that document the reader's and performer's shifting encounter with the estate over the course of the play. Rather than addressing the history of the estate in chronological order it is organised according to viewpoint - how others have conceived, perceived and represented it. It begins from the perspective of the most distanced observer and finishes with the most intimate user. This is mirrored in the mode of narration, written from third to second to first person; and in the physical location of the tour group, moving around the public outer edge of the estate, into the open courtyard and onto the semi-private balcony.

I incrementally dress up in eighteenth century costume like the estate's neo-Georgian architecture, adding an item of clothing as I cast myself as different figures who have shaped the estate by the way they have looked at it - a Victorian surveyor, journalist, jogger, politician, architect, sociologist and resident - ending with my personal relationship to it; the luggage that I use as costume and stage, the same one in which my mum slept for her first year when my grandparents emigrated to London from Sicily into an identical estate in Clerkenwell. 
During the performance I choreographed encounters with residents to interrupt the audience of seventy visitors expecting a traditional architectural tour with moments of creative participation. They were confronted by a building and community holding its own telling. I wanted to neither privilege residents nor visitors as the official audience; so the roles of observer and actor differ when the script is performed and read. When enacted on site, it is performed as a tour to a visiting tour group as audience. When read, the movements of both tour guide and tour group are seen as directed and controlled through stage directions, with unseen residents observing as the true audience. This has the dual aim of opening up the site and debate to wider audience while also revealing representations of the estate back to its inhabitants.

Before drawing conclusions on the act of sharing research in public, it is important to address the institutional and artistic context in which such work is situated. At a time when public higher education is starved of funding under austerity measures, academic knowledge is measured in terms of its 'impact' and academics are subject to ever increasing time and pressure demands 'to perform a diverse set of roles in a range of contexts (research, teaching, administrative, marketing, departmental strategising, widening participation, policy input)' (Askins 2009: 11). Public engagement should not be expected of all scholarship when, as geographer Rachel Pain explains that 'having to excel across the board at everything restricts the depth of thought and skill put into any one activity', exposing the idea of public good to the 'threat from marketisation and shallow audit rather than deep accountability' (2013). However, she continues, 'there's a moral argument for sharing the resources we have with communities and organisations that have been hardest hit by recent cuts...' (Pain 2013). Publicly funded art faces the same brutal pressures, uniting theorists and critics with concerns that artistic work will acquiesce to the demands of state and capital. This is a seen as a particularly intractable issue in the work of artists who take social relations as their material (described variously as participatory, relational, dialogical, new genre public, socially engaged, collaborative) with conceptual origins in radical projects of the 1960s. Art historian Larne Abse Gogarty states:

We need to recognise that the further retrenchment of state provision and deepening recession since 2008 have pushed frequently well-meaning socially engaged artists towards plugging the gap in providing social services where they risk endorsing the logic of austerity. (2014: 9)

I will close with some personal considerations for the researcher contemplating publicoriented practice. On one hand, sharing work in public can open research to the possibilities of more socially critical purpose, giving life and joy to studies by gathering in new communities. Immediately after my performance, clusters of visitors and residents continued to trade stories and experiences that elicit empathy and enact difference in a way that strengthens, not fragments, in common principle. On the other hand, sharing work summons the practitioner to confront their own presumptions and ethics. Reading the script a year later I feel unease at a failure to balance its comprehension with complexity. To craft a clear narrative, I drew neat distinctions between differing viewpoints that concealed their nuance, allowing ideas half-formed to ossify through utterance and foreclose any alternative readings. To give equal voice to those who had written about and lived in the estate, I neglected the voices of the five critical thinkers through which I had come to understand it, reinforcing a distanced and privileged position whereby I shared what I knew not how I came to know it.

If there is a message in this confessional it is a simple one, a plea to share research in order to find your voice by finding common cause with others, and to allow your work to be opened 
up to criticism, from others and from yourself, in order to share better. I invited feedback by asking residents and visitors to complete an open-ended form after the day of performances had concluded. From their responses, some left challenged, others left cheered, and one startled me in its honesty, reinforcing the ethical responsibility of such work. Rather than the moment of hope in the closing rallying cry, I regret that it was my opening eulogy that stayed with her. 'Why are you here?' one question asks. 'A funeral I guess' she responds. 'What have you learnt?' asks another. 'That I have no place in the future and I didn't appreciate enough what I had in the past.' 


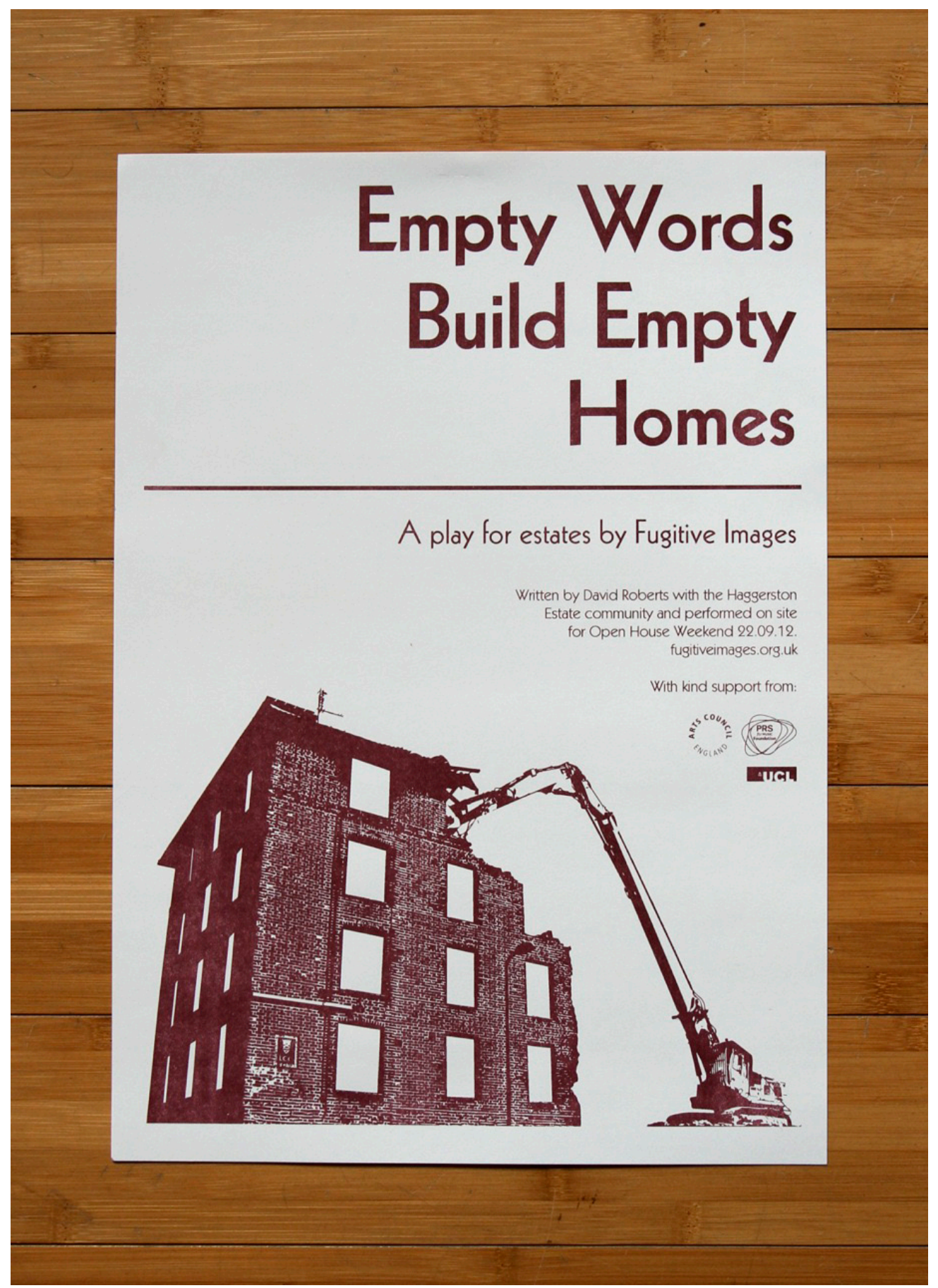

Figure 1: Poster for Empty Words Build Empty Homes. Source: Author. 


\section{Empty Words Build Empty Homes: A Play for Estates Prologue}

The story takes place half a decade after the latest economic meltdown (in this case, 2012). The stage a housing estate somewhere deep in the inner city (in this case, the Haggerston Estate in Hackney). One block as ESTATE, one actor as GUIDE, one as NARRATOR, twenty as tour GROUP.

The GROUP assembles in the south-east corner of the estate's inner courtyard concealed by a projecting wall. They stand on unmarked tarmac which continues up to the edge of a low wall that runs in front of the gated doors of ground floor flats. Down pipes and green plastic window boxes adorn the facade either side of a window filled with breezeblocks.

The audience is scattered across the rest of the courtyard and along the four rows of long curved balconies that form the two-sided five-storey block. The play unfolds while they peruse newspapers on patios, hang clothes from balcony ceilings, play ping pong by picnic tables, water pansies in hanging baskets, share lewd jokes by open gates, steal kisses in the stairwells, cycle feverishly on the grass patch protected by stabilizers. Some catch glimpses of small talk from the gathering GROUP, others spy the NARRATOR and GUIDE descend from a top floor flat.

Only the GUIDE reaches the ground, a bespectacled man in a black $t$-shirt, dirty plimsolls and dark jeans. He hauls a tired leather suitcase to the tarmac before the GROUP, steps onto it and clears his throat. A hush descends. Before he speaks the NARRATOR appears from the first floor balcony above, a petite woman who looks past GROUP and GUIDE to address the scattered audience.

\section{The NARRATOR}

[To the audience] Excuse me please my neighbours, with your grace

I shall explain our presence in this place, a short interval interrupts your day while players do a tragic tale convey. Your Haggerston still stands but only just soon balcony and promise turn to dust. Our characters: this tour group huddled here drawn by their curiosity and hope to peer in through your windows to this building's past; a guide who'll challenge prejudice and cast himself as planner, politician, hack, as writer, jogger, architect and back to blame his kind for gentrifying spaces which still belong to others, (see your faces in the bricked up windows of this block) so listen to him and forbear to mock his heavy glasses, skinny turned-up jeans perhaps he sounds pretentious, but he means to show them everything you stand to lose when we forget your homes behind the news. He'll take them on a journey - not through time but through the eyes of others, peel back the grime 
of preconceived ideas and try to look

in social housing's quickly closing book.

So please be patient and save your debate

till he has introduced this great Estate.

The GUIDE

[To the GROUP] Welcome to the estate.

Ladies and gentlemen, thank you for being here.

Thank you for caring.

This building will fall in a matter of days.

[Turning to face the building, outstretching his arm and speaking slowly] It's great to meet you, here, face to face.

[Turning back to the GROUP] Please make time to get to know it.

Please [pausing] touch anything.

[Gesturing to the right of the GROUP] The ballet of cranes above herald the future. City Mills, a collection of contemporary apartment buildings, an inspiring prospect for anyone seeking a convenient central London lifestyle.

So is this a tour or a viewing of an open casket? A museum or mausoleum? Perhaps it calls for a different beginning, [turning to face a projected brick refuse chute behind] this, [touching it] my pulpit.

The GUIDE ascends a small flight of stairs onto a raised platform. A kettle boils and some audience members congregate to watch from a distance with mugs in hand. The sound of their chattering and clinking and sipping drifts in and out from now to the end of the prologue.

[Looking down to the GROUP] Ladies and gentlemen we are gathered here today on this solemn occasion to remember Haggerston.

We stand in the shadow of the last of the family, Samuel House, where once proudly stood six.

86 years old, his siblings have already passed; Richardson, Pamela, Lovelace, Lowther, Harlowe. There are no stones to tell you where they are laid. No flowers to mark their passing.

What can a building tell us while it still stands? Do we look at it from its past, fresh off the drawing board in 1936, or now crumbling and half empty in 2012 ?

Are we interested in what it represents, what lies beyond it, or what it is? Is this a eulogy for Haggerston or for social housing across the capital? 
The GUIDE descends the stairs and begins walking to the corner of the courtyard atop the small brick wall that marks the front porch of ground floor flats.

How to start? Trace this cavity in the grout? [Jumping to wall of next flat] Measure yourself against it. Caress concrete. Lick brick. Hug ironwork. [Jumping to wall of next flat] Press ears against the chute. Sniff sash? Jump up and down? [Stepping down at the end of the wall] Or perhaps, just walk around.

\section{Act One: At}

The GUIDE strides out of the courtyard and around the block. The GROUP join and slowly assemble around him in the middle of a narrow alley. A black painted hoarding cuts across the grass verge and ends by a thin strip of cobbles where the alley meets the road. Most of the audience return to their pursuits, others follow the play but observe from afar until it ends. Behind The GUIDE a plain redbrick wall fills the view interrupted by a solitary light from which hangs a PHOTOGRAPH OF A SLUM DWELLING, a sepia-tinged image showing the front and rear of a ramshackle terraced house. He lays down the SUITCASE and extracts a thin white RUFFLED SHIRT.

Imagine this great building away, like the other angular blocks that were here. The brink of the Twentieth Century, a golden Victorian morning. Dickens, fog, the metaphor that linked houses of the rich and poor in the Big Smoke, inside and out.

In its place two-storey terraces nestle beside one another. Slums, some called them. A dense grid filled the entire block.

[The GUIDE takes the PHOTOGRAPH from the wall, and holds it behind the RUFFLED SHIRT which gently billows as he continues] The social reformer Charles Booth was critical of sensational accounts of poverty of the time. He began a great survey of London that lasted seventeen years, to substitute conjecture with reason.

He said [reading from the back of the PHOTOGRAPH] 'East London lay hidden from view behind a curtain on which were painted terrible pictures: starving children, suffering women, overworked men...' The writers have... tried to lift this curtain [whisking off the RUFFLED SHIRT, slipping his arms in and beginning to button up] and see for themselves the world it hid.

[Looking up] Fearing his own prejudices, Booth did not visit the streets to gather data. Instead the work was compiled by others.

The GUIDE turns the photograph to reveal Booth's SURVEYOR'S NOTES to the GROUP printed on the reverse, comprising handwritten notes scribbled loosely within guidelines. He walks out from the alley onto Dunston Road. The sound of chattering fades, replaced by the tinkle of bicycle bells, the light step and puffing of joggers, the birdsong of geese, coots and seagulls. The facade of the block comes into view. On the corner a tiled plaque reads SAMUEL HOUSE. To the west of it begins repeating columns of sash windows, five high, a great number of which have been filled by giant passport-style portraits. Two geometric bays and a smattering of large circular and small elliptical satellite dishes break the uniformity of the facade.

By Regent's still water, the surveyors of Booth once took with the swagger of middleclass moralists. Side by side with school board visitors they noted every family they could see or knew of, scribbling in the margins. 
[Reading from the SURVEYOR'S NOTES in his palm and gesturing to the right of the GROUP to a portrait of a woman with tangerine waved hair and a grey-green vest] A painter with six children, [gesturing to a portrait of a woman with a blonde perm, two necklaces and a denim jacket] horse keeper, [to a bespectacled man, orange polo-shirt and black jacket] glass blower, [to a bearded man, asymmetric fringe, red t-shirt and black jacket] Italian cabin boy whose wife runs a local shop with twenty-five in his family, [to a woman with sunglasses on her head in an orange t-shirt] gas fitter, [to a woman with gold hoop earrings, long black fringe and diamante-studded shirt] butcher with eight kids, [to a woman holding an acoustic guitar with frizzy black hair] chimney sweep with one, [to a man with shaved head, goatee and royal blue hoodie] drunken boot maker with four, his wife a clothes washer, [to a woman with dreadlocks, yellow-green hairband, long earrings and black jacket] three men beating out tin at the back of a yard. [Looking up from the SURVEYOR'S NOTES] At the end of the chapter they conclude [and back down] a great many poor but much of the poverty here is due to drink - women may be seen continually going to and fro with cans and jugs of beer. There is a great deal of disease - not only now, but whenever there is an epidemic it always seems to reach this street.

The GUIDE crosses the road. A black painted railing and sparse trees separate pavement from towpath. Across the canal the newly planted landscaping of the Bridge Academy lines the embankment. The GUIDE sits on the SUITCASE, back to the GROUP facing a beige MAP of London poverty 1898-9 coloured in shaded bands of yellow, red, blue and black that hangs from canal railings. He holds the MAP above him.

Booth and his secretaries received these notes and aggregated these personal accounts into a portrait of society. His map defines and identifies social classes, arranges them hierarchically by colour, and locates them, a new language to understand class and space.

[Pointing to the bottom of the MAP] Clarissa St the pink of [reading from the MAP] mixed, some comfortable others poor, [looking up] the streets behind the dark bruise of [reading from the MAP] very poor, casual, chronic want [looking up] and here along the Canal, where Samuel House stands, the thickest licorice of [reading from the $M A P]$ lowest class, vicious semi-criminal.

[Looking up] The terraced rows behind blacken and crumble under his condemnation. In its place rises Samuel House in the late 1930s, built by the architects of the London County Council Housing Department, sash windows all visible back then. Glimpses caught of new residents half obscured by pristine net curtains.

[Turning around the MAP to reveal a NEWSPAPER] The journalist. Always prepared to celebrate or condemn with their pen. At first they capture Haggerston's golden moment, the excitement of its new tenants at a time when so many were suffering from rogue landlords, squalid unsanitary conditions and bathrooms out the back. But common woman and man can never spend long in utopia.

[Taking a TIE from the SUITCASE] The estate's first resident was a Mr. Vandermark. [Putting on the TIE] But the old man couldn't imagine life in an urban apartment without his livestock, and gassed himself in his brand-new fitted oven. 
The GUIDE crosses the road. Six windows on this section of the facade are roughly filled with breeze blocks. The timber frames of the surrounding sash windows are stained with rot.

Over its life, the journalist witnessed the bricks crumble, sills crack. Those that visited in the seventies wrote of residents that fought desperately for refurbishments, rent strikes over the state of damp, but were jilted and jerked around by modernisation plans on hold due to economic restraint of the GLC.

[Gesturing to a portrait of a man wearing a blue tartan flat cap holding a opalescent accordion] 1973, Mr Golding forced to move all his family's furniture into one room for the damp taking over their flat, eating Christmas dinner on the foot of the bed, [reading from the NEWSPAPER] doomed to continue living a ghetto existence, [looking up] the article declares.

Over time the personal stories are replaced by rumour, relying on anecdote, multiplying worst case scenario. At some point Haggerston was typecast the heroin capital of Europe. These selectively edited stories echo across the city; at the same time that they personalise, they render faceless and voiceless.

Of one housing estate, the Daily Mail, of course, just last year wrote, [reading from the NEWSPAPER] yes, life... looks grey and bleak. But by the standards of Mumbai or even the poorer parts of Philadelphia, the people... are not poor in material terms. Yet most of them are foul-mouthed, lazy scroungers, cheats, layabouts, drunks, drug addicts - who are totally dependent upon the goodwill of taxpayers.

[Looking up] To them, the building is decaying because the morals of those inside are. [Gesturing to a portrait of a woman with cropped hair and black $t$-shirt] Their social collapse so powerful it brings the housing down with it.

The GUIDE crosses the road. Moored below a willow tree in the canal are two narrow boats. Beside them the red surface of a kayak launch is worn to grey through use. The GUIDE pauses at a PHOTOGRAPH of boarded up windows hanging from the railing depicting Samuel House covered not with giant portraits but orange HACKNEY HOMES boards. He partially undoes his TIE, twists it backwards and fastens it around his forehead as a hairband.

The commuter, cyclist, dog walker, jogger only pass through, lycra-clad, headphones, sweatbands never time to stop and unpick.

The fleeting observation of the jogger is a first-hand so brief, they see a community defined only by its crumbling facade.

When orange boards suddenly appear over the windows of empty flats, they are heard on the canal confessing. [Reading from the PHOTOGRAPH] Council flats, you can tell from the satellite dishes. Pretty minging. Looks completely derelict, presumably there are people living in it, but I wouldn't want to. The dirty net curtains, things behind windows. Frightened, intimidated. It's getting oranger and oranger, the orange is winning. 
[Looking up] Their voices filter through open windows. Overnight those orange boards change to the faces of people. The jogger doesn't know what brought about thischange. They only notice that their pace is different. They have slowed to look where before their step quickened.

The GUIDE stops at the crossing of Dunston Road and Clarissa Street. He faces away from the corner of Samuel House. Behind him is a municipal map of the estate mounted on steel plate. Further behind, the corner of the facade wears signs for SAMUEL HOUSE, CLARISSA STREET and LCC. He pulls down the TIE around his neck again.

At this crossroads the developer and contractors now stand. [Reading] Out of time, Dickensian, [looking up] one called it in a meeting. In its place they wish to build contemporary blocks that house [reading] lively, diverse, vibrant communities, inviting young city workers to play the regeneration game. [Looking up and turning the PHOTOGRAPH to reveal a set of images of a robber, drug addict, prostitute and paedophile] They pitch for a CCTV system to be installed, to prevent the dangers of living here.

They can no longer see the architecture it responded to when it was first erected. The Georgian terraces there, another redbrick block here, long gone, the world around it has changed.

The GUIDE puts down the SUITCASE by a low wall as a step and crosses between a gap in the box hedge into a freshly mown grass perimeter. He stands framed by the rear of the green painted tubular steel sign facing Samuel House. Half of the GROUP line up on one plane facing south, the other facing west.

So what does this building see now? This is the view. Look at the overlapping times of its surroundings.

60s high rises, 70s mixed, 80s low, 90s not much but for buildings in the city, 2000 the rise of the canalside apartment, wharfs and quarters and yards. Directly opposite, the Bridge Academy sponsored by UBS, the Laburnum boat club beside it. Rhythms and cycles of style and desire.

What you can't see; [pointing to a MAP attached to the back of the sign showing London in 1937 dotted with circular red stickers labelling newly-built LCC block dwellings] the other identical ones to Samuel House, all across London.

[Gesturing right] Just down the road Whitmore, [gesturing left] that side, Whitsun, [gesturing right] beyond it Provost, [gesturing left] beyond that Pritchard's. Each with the familiar inter-war serif and shield of the LCC.

[Putting on a BROCADE JACKET]. The politician. Reforming with the Housing Act of the 1930s. Booth's map was top of the pile of their in-tray, a diagram for social reform. Those same areas of black and blue quickly replaced by LCC blocks, there were over a hundred like this across the city. The architect a tool of the politician. 
But war hung over the decade. Prime Minister Lloyd George's great speech called for homes fit for heroes to be built for veterans of the Great War. Was it Booth's dark bruises they wanted to heal, or a slum solution to erase the seedbed of revolution? For the government, it was later revealed, was desperate to quell an uprising on these shores. [Reading] Housing to give a sense of confidence in the status quo, [looking up] no need to revolt.

The GUIDE walks along the grass perimeter and rests by a NO FOULING sign on which hangs an insanitary areas MAP showing the terraced rows that stood here before stained a deep red and crudely crossed out. The ground floor windows are entirely bricked up while above large portraits are interspersed among sashes.

The Housing Act gave the power to demolish properties unfit for human habitation, clearing more slums than any time previously. Insanitary conditions lead to selection for demolition.

[Undoing his top button, removing his TIE and taking down the MAP] The modern politician, no tie of course, chooses a much more effective method, condemnation by metaphor.

Sinks. Why do they insist on calling these sinks? What makes a sink? Well, sinks were what was new here - in kitchens, bathrooms, washhouses. What makes it a sink for the politician today? The buildings? To contrast with the blocks that often rise so high. Its residents? That all their morals have drained away. Metaphors are laden - overspill, they say when there are too many, decant, when they want them out. Materially and socially a waste.

Margaret Thatcher described buildings like this as socialism made concrete, with distaste. And she coined the term social housing as she declared there was no such thing as society. Architects would describe it as socialism made concrete, with relish. Social housing to build a new society.

The GUIDE steps out from the grass perimeter into Clarissa Street, turns over the map to reveal an ELEVATION of the estate, stands on tip toes upon the SUITCASE and hangs it from the parking sign beside him. Along the ground floor, curtains behind sash windows are all visible, rows of portraits line the windows above.

Imagine those faces gone if you will. Plans, sections and elevations rarely include people.

The architects. It is from this vantage point that you are able to see their imprints. Walls of solid brick, floors of steel and concrete, pitched roofs of timber and tile. A five storey red brick neo-Georgian reformed urban perimeter block. Facades with an undulating rhythm of sash and bay, other blocks that stood here curved with deep crescents and gardens, all with grass forecourts granting privacy. Three pubs and a parade of shops between blocks to serve the new neighbourhood.

The architects visited Hampstead and travelled to Copenhagen, Vienna, Leipzig, borrowing the respectable language of the houses of the well-to-do, vicarages and 
schools, and claiming it for the worthy working class. The poor made good. The values of the Arts and Crafts movement and early English modernism stripped down to austerity. Honesty in construction, truth to materials, but mostly domestication within economy.

But the architects warned, [reading from the ELEVATION] it is true of aesthetic appreciation that the quiet good manners of today may be out of vogue tomorrow.

The GUIDE walks to the end of the low brick wall onto curbstones dented from heavy vehicles. An alley separates it from the courtyard beyond, little remains of the grass on the verge.

Fashion in form and name. The modern developer chooses to call their new blocks [pointing behind the GROUP] Ability Plaza and Avant Garde Tower, both newly opened in Hackney. But here [pointing to tiled nameplates of SAMUEL and HARLOWE HOUSE framed by a change in texture of brick at the corner of the facade] we find Samuel and a hint of Harlowe over the hoarding there. Who held this power to name? The architect, the councillor, the librarian?

Names make categories that create boundaries, to shape the social relations, to tame the inhabitants of this brave new world into order.

Whoever it was would have noted the street - Clarissa - sharing its name with the longest novel of the English language, written by Samuel Richardson, another social reformer and novelist from the 18th century.

[Putting a WIG on] With a lyric tongue, a fire in his heart and a pen in his hand, he wrote to reform, to awaken virtue in his readers. The stories he sold now house the poor, their titles above the door.

This unknown figure named Haggerston in Richardson's honour, dividing it spatially. [Pointing left] Samuel and Richardson house at the bottom by the canal, the author in full. [Pointing right] Lowther and Lovelace at the top by the park, two distinguished protagonists. [Pointing behind] Harlowe and Pamela, the two great heroines in between, backing on to one another.

A perimeter block shielded by virtue, Richardson's ideals made concrete, the poor made heroic.

\section{Act Two: With}

The GUIDE reenters the courtyard from an alleyway at the opposite corner, dressed in RUFFLED SHIRT, BROCADE JACKET and WIG. On one side the black hoarding runs into a brick wall demolished above ground floor level. On the other, the pavement turns the corner and meets a blackboard affixed to the plain redbrick wall leaching chalk into the masonry below.

What happens when you negotiate this threshold of virtue, this open relationship between courtyard and street? Is the rest of the place shot through with references? [Gasping] Don't say that. Don't you know where you are? [Jerking right] Dodge the crossfire. [Clapping hands to face and dropping the SUITCASE] Oh my God! You live here, and you haven't been shot? One teenager here was asked by her schoolmate. 
In here you grapple with a language of virtue in which not all are fluent. Stories of crime are legion. Lovelace House was the worst. Always robberies, often a hearse. Last to be built, different architecture you see. A staircase either side, balconies linked between. You could escape, if you were a villain.

Lovelace, in fact, was not virtuous for Richardson, not at all. A rapist, the cruelest villain in literature. Life imitating art. But it all looks pleasant, safe even. And it was at the start.

The GUIDE stands on a low concrete bollard painted with spots on which leans an image of a vivid orange book I LIVED IN A SLUM. Other painted bollards mark a division between the tarmac and paving of ground floor flats. The road sweeps around a central patch of grass lined by trees and hedges. Opposite, the balconies of the estate form a perimeter wall around two sides of the courtyard.

Mrs Cecil Chesterton, took up residence in various London slums at a time when they were regarded as a seat of social problems. Her pioneering account of Haggerston a year after it was built in 1937 is an honest celebration of the warmth of working-class life.

[Reading from I LIVED IN A SLUM] It is a pleasing feature on the landscape. The flats are well planned, and the construction appears to be very sound... The people... manage their own community, and bring mass pressure to bear on any individual who disturbs the public peace. The community spirit has survived the slum; the attractive balconies and wide passages have taken the place of the doorstep.

[Looking up] Whereas giant pictures of faces now look out to the canal and street, in here the same faces look out from balconies onto the courtyard. Ones that call you by your name. Or call you out as a stranger. Chesterton witnessed this gentle system of social observation in the courtyard first hand. What did she see?

[Turning over the book image to reveal a sepia-tinged PHOTOGRAPH of an empty courtyard] Open, free, unprogrammed space. So rare in the city. Never in new plans. No entryphone no keyfob. But also no landscaping then.

These vast communal courtyards had nothing but sheds, children play in puddles, mothers look on. A wall so ignored there wasn't even graffiti on it.

[Pointing to corner] Behind the hoarding once stood the pub and beside it the flat of the resident caretaker, a sign of maintenance and repair built into the fabric of the blocks.

He kept these empty swathes of land neatly trimmed. Scrubbed on his knees. Painted on tip toes. Swept endless surfaces. Only to be told he was no longer necessary. He only witnessed the beginning of the decline here. The widespread dismissal of resident caretakers of the 1970s, followed by the Right to Buy of the 80s, the Buy to Let of the 90s and the historic low of social housing construction since. Clean lines fade and weather with political will. A gradual vacation of ideals and tenants not even the powerful and proactive tenants association here could rescue it.

The GUIDE walks between hedges and flowers planted in tyres and climbs atop a timber picnic table. Beyond him, between the leaves, ground floor walls are adorned with painted murals of 
four trees in different seasons. A vivid figurative painting of a family covers the door to the refuse area beside.

In 2007, the orange boards came up overnight without warning. One resident said, [reading from PHOTOGRAPH] every time I approached the estate, I would look at them and have that kind of like, ugh, drop in my stomach and feel slightly nauseous and upset. It did just give the estate the look of somewhere that was completely condemned, I didn't feel that that was an accurate portrayal of actually what it's like to live here. It looked like it had been bombed out. That's how it made me feel, like an ex-war zone.

[Looking up] Five months later residents were given a vote. For ownership to stay with Hackney Council, the despised orange boards to remain in perpetuity. Or for a stock transfer to L\&Q Housing Group, complete demolition in two phases, guaranteed rehousing for all tenants. Seventy-one per cent voted in favour.

Whilst waiting for their new homes to be built, residents' abandon has been replaced by agency. After thirty years of powerlessness, they have been granted freedom and funding to use every space, to fill it with expressions of themselves, a cathartic release to finally make it the place they want it to be.

That same resident used to look onto this baron courtyard from her flat and wonder what it could have been, now that she's instigated the transformation. [Reading from PHOTOGRAPH] It's trite, [looking up] she says, [reading] but it's amazing what a lick of paint can do.

\section{Act Three: Within}

The GUIDE walks to the stairwell in the corner of the block and steps within. The front door at the base of the stairwell is surrounded by a steel frame. Above it pansies are planted in a hanging basket. Beyond it a green felt notice board displays forthcoming community events.

Up close we see a place of everyday ritual - grubby handprints, tyre marks, scuffing, walls scored by handlebars, steps worn shallow, the mark of a walking stick.

As we ascend these stairs, we follow one resident, John, who lives on the fourth floor, with Parkinson's for the last few years. We emulate his pace, carrying his bag of shopping and stick. Slow time down to his painful rhythm.

Count the steps. 8 per half landing. 2 per floor. 4 floors. 64 in total. Hell, as John calls it, stuck in this prison, he laughs. Hold on to the continuous twisting handrail as we climb.

The GUIDE slowly ascends stairs of cast concrete with large aggregate and missing instep nosings. The black iron handrail surface is made uneven from previous layers of paint. After two storeys, the GROUP pass three members of the audience leaving a flat, jostling them against the railing. The pace quickens after and they climb all the way to the top.

We end our journey up here on the vast sweeping concrete cantilevered balconies, curved in the corner, envisaged as the terrace doorstep stretched. 
The GUIDE lets the GROUP pass him and file along the left hand balcony, between flat and wall topped with triangular ornamental tiles and occasional breaks filled with small iron railings. Windows and doors have been bricked up to all but one of the four flats on this balcony which continues around the corner ending with a protruding column of sash windows.

From here you can cut into and imagine spaces the designers sought to create beyond. Stand outside, anticipate the unfolding lives within.

[Gesturing to the bricked up flat behind] Divide into rooms, all rigidly planned, categorised and delineated. Openness and light to sweep through double aspect flats. Eight feet six inches high, living room one hundred and sixty square feet, bedrooms one hundred and twenty square feet, separated from the water closet and bathroom, all connected by the entrance lobby. Every corner curved. The vision of a mother in the kitchen at the front looking over to children in the balcony and courtyard. The father in the parlour in his privacy at the back.

Each floor was built with a washhouse and communal drying room. But now these are moulded into something new. A cat curled up on a sofa where the lathe once stood. A copper made into an office, a winery, a sewing room, artists' studios, some patched with mould and cool with draft, some rich in colour and character.

[Facing the GROUP] Those views of passersby on the canal, from outside looking at, talking of grim blocks, dirty net curtains, dereliction, were overheard by two residents living on the top floor, trained artists, it didn't match their everyday experience looking from here, out onto the courtyard, of people playing ping pong even in crummy weather.

They understood the real Haggerston is not made of concrete but flesh. It is from here that they mounted their response. Door to door they went to get support, to replicate the faces they saw within to those outside.

They took portraits of each inhabitant and bolted over the orange boards that covered the windows of empty flats. The building, once an anonymous mask of fear and decline, is now a face of everyday humanity, meeting the gaze of the onlooker.

From here we can name the portraits on the facade, that surveyors like Booth could only point to, the residents that live in an artwork. We can draw lines of connection between them - Gillian in the top-right corner above Helen, a hairdresser whose salon was in Lovelace House, between them Paul, now in Istanbul but his memories bound in books in boxes under beds remain, below Maciej. Further along, Pam, tragically just passed away, used to run the food co-op every Thursday with Tina, next to her. At the other end, Ruth-Marie, who instigated all of the murals and table-tennis and community parties, Eric a former coral free-diver and Steve, a film distributor, met for the first time in 25 years the other day, Lorna a welcome calm at every meeting, beside Lasse and Andrea the artist-residents who re-humanised this block, a friendship made stable by this heavy brick, who laugh with and care for John, on the top left corner, and learn to play using his accordion.

This is a real community. There are arguments. There are orgasms. These are good people. 
[Pointing to the broken tiled roof behind the GROUP] Look behind, carefully, and you may see the final residents of this place. The unwelcome ones that know the block most intimately, that scavenge, destroy and recycle.

The rats that gnaw holes in the cavity wall, the pigeons that have split apart the weathered, cracked tiles that now nest in an empty bricked over flat with one window accidentally left ajar. Holes in the roof have battered the ceiling and patience of its topmost residents.

There is no one Haggerston. From absent man of Booth to ever present residents, there is no one story. To live here is to occupy a space that forever shifts under your feet. Ideals that change hands more frequently than tenants. Haggerston was built for shelter, to give proper light and adequate space. But also health, stability, dignity, equality, reform, community. But this didn't always work out. To others, it is simultaneously a home, factory, prison, symbol, stigma, utopia, grace and despair. To me?

The GUIDE kneels before the GROUP and opens his SUITCASE, a rectangular leather trunk with metal clasps and corner plates. Remnants of peeled off labels cover the lid. The interior is lined with stained, striped paper.

I've had the opportunity to hear balanced viewpoints to formulate my own. I live in a flat nearby, I know very few of my neighbours. I enjoy the peace here. I enjoy the pace here. The quiet and spirit. Architecturally this block could be anywhere in London, but the residents have made it a place, and the community they have carved here feels different. But we come to these positions from something much deeper. Mine is no different. Which brings me to this suitcase.

[Removing the WIG and throwing it into the SUITCASE] I was raised by storytellers. Migrants clinging to their great pilgrimage after the war from Sicilian hillside village to a tiny council flat in grubby Clerkenwell. Gran destino, my nonna, my grandma, whispers, meaning great destiny, her eighty-nine year old eyes gleam. When she really means clandestino, illegal immigrants. Updated and mutated as her decades have passed.

[Removing the BROCADE JACKET and throwing it into the SUITCASE] They came to London with one suitcase, like this, full of possessions, belly big with child - my mum, who was born and slept, night after night for her first year in the same case. Our collective memory, our spoken history packed tightly and preserved under leather.

[Removing the RUFFLED SHIRT, throwing it into SUITCASE and shutting the lid]. As a way of holding together our growing family, every story is related back to her journey across the continent with my granddad, that suitcase in that council flat in that block. A place of little material comfort but emotional permanence. They left the block but it didn't leave them. Passed on to me in a childhood full of stories.

This suitcase a physical reminder that, for all the opinions I gather, I am a visitor here.

\section{Epilogue}

The GUIDE, dressed as he was in the opening act, walks to the end of balcony followed by the GROUP in single file. From this point the central courtyard is visible and beyond it the backdrop of a new housing development under construction. Cranes swing across the skyline. 


\section{NARRATOR}

[To the audience] The story of your estate did not start, with the first brick, nor will its soul depart when the last wall has fallen and this ground is site for new homes, occupants unbound by this nostalgia, memory and hope that lingers still for those with strength to cope with damp and height, and pressure of those caught when good intentions of the past fall short. We stand and view beginning and an end the City Mills draws closer and will rend your small last flourish of community, faint echo of what planners hoped would be. While this scene ends, blocks like Samuel remain throughout the town this play will run again. The tour group here uncertain, each must choose tear down, rebuild, refit, repaint, reuse? Bold future or a fear for what we lose?

While it still stands there's time to form their views.

\section{GUIDE}

[To the GROUP] Trace this cavity in the grout, [running his index finger along the ridge between breeze blocks] can you feel the moment between departure and nostalgia? Measure yourself against it, [standing arms outstretched with back against the bricked up door of a house] can you sense the distance between neighbours? Caress concrete, [sweeping his hand across the floor] does it feel daunting? Lick brick, [rolling his tongue over a painted brick] does it taste rotten? Hug ironwork, [wrapping himself around an iron gutter pipe] does it seem antiquated? Press ears against the tile, [squashing his ear to the balcony wall] can you hear its lost ideals groan. Sniff sash [pressing nose to glass] does it smell hopeless? Jump up and down, [launching himself off the floor] can you feel it sink?

[Gesturing to the left of the GROUP] The City Mills rises, a collection of contemporary apartment buildings, an inspiring prospect for anyone seeking a convenient central London lifestyle.

Please [pausing] touch anything.

I do hope you will make time to get to know it.

[Looking out to City Mills, extending his hand and shouting slowly] It's great to meet you, here, face to face.

[Returning his gaze to Samuel House]. This building will fall in a matter of days.

Thank you for caring.

Ladies and gentlemen, thank you for being here. 
Welcome to the estate.

The GUIDE picks up the SUITCASE, descends the four flights and joins the audience below chatting in the courtyard.

End. 


\section{References}

Askins, K 2009 'That's just what I do': Placing emotion in academic activism. Emotion, Space and Society, 2(1): 4-13. DOI: http://dx.doi.org/10.1016/j.emospa.2009.03.005

Benjamin, W 1968 The Storyteller. In: Illuminations. New York: Harcourt, Brace \& World, pp. 83-109.

Brecht, B 1957 Brecht on Theatre: The Development of an Aesthetic. New York: Hill \& Wang.

Crouch, T 2007 ENGLAND. London: Oberon Books.

Edwards, M 2011 London for sale: towards the radical marketization of urban space. In: Gandy, M (ed.) Urban Constellations. Berlin: Jovis, pp. 54-7.

Forty, A 2013a Architecture in Nineteenth and Twentieth Century Britain, UCL MA Architectural History module notes.

Forty, A 2013b Keynote. In: The Society of Architectural Historians of Great Britain Graduate Student Forum, London, UCL on May 32013.

Foster, E and Heighes C 2011 The Earth, a Good Apartment. PAJ: A Journal of Performance and Art, 33(2): 18-25. DOI: http://dx.doi.org/10.1162/PAJJ_a_00034

Gogarty, L A 2014 Art \& Gentrification. Art Monthly, 373: 7-10.

Hatherley, 02012 The film-makers creating trouble on the estate. The Guardian, 13 September.

Hodkinson, S and Robbins, G 2013 The Return of Class War Conservatism? Housing under the UK Coalition Government. Critical Social Policy, 33(1): 57-77. DOI: http://dx.doi. org/10.1177/0261018312457871

Jones, 02011 Chavs: The Demonization of the Working Classes. London: Verso.

Kaye, N 2000 Site-Specific Art: Performance, Place and Documentation. London: Routledge.

Lees, L, Just Space, The London Tenant's Federation and Southwark Notes Archives Group 2013 The Social Cleansing of Council Estates in London. In: Campkin, B, Roberts, D and Ross, R (eds.) Urban Pamphleteer 2: Regeneration Realities. Northampton: Belmont Press, pp. 6-10.

Manis, S 2009 Writing as Performance: Using Performance Theory to Teach Writing in Theatre Classrooms. Theatre Topics, 19(2): 139-151. DOI: http://dx.doi.org/10.1353/tt.0.0072

McAuley, G 1999 Space in Performance: Making Meaning in the Theatre. Ann Arbor: University of Michigan Press.

McGuirk, J 2012 Unreal Estate. Domus, 30 July. Available at http://www.domusweb.it/en/ architecture/unreal-estate/ [Last accessed 10 February 2014].

Moss, S 2011 The death of a housing ideal. The Guardian, 4 March.

Pain, R 2013 Research capacity is our greatest resource, and collaboration at any level has the potential to make for excellent research. LSE Blog, 11 February 2013. Available at http:// blogs.lse.ac.uk/impactofsocialsciences/2013/02/11/5-minutes-with-rachel-pain/ [Last accessed 10 February 2014].

Pearson, M 1995 From Memory: or other ways of telling. The New Welsh Review, 29(8): 77-83.

Pearson, M 2010 Site-Specific Performance. Basingstoke: Palgrave Macmillan.

Phelan, P 1993 Unmarked: The Politics of Performance. New York: Routledge. DOI: http:// dx.doi.org/10.4324/9780203359433

Phillips, A and Erdemci, F (eds.) 2012 Social Housing - Housing the Social: Art, Property and Spatial Justice. Amsterdam: SKOR.

Rendell, J 2010 Site-Writing: The Architecture of Art Criticism. London: I.B. Tauris.

Slater, T 2013 The myth of 'Broken Britain': welfare reform and the production of ignorance, Antipode, 45: 1-22. 
Watt, P 2008 'Underclass' and 'ordinary people' discourses: Representing/ re-presenting council tenants in a housing campaign. Critical Discourse Studies, 5(4): 345-357. DOI: http://dx.doi.org/10.1080/17405900802405288

Watt, P 2009 Housing stock transfers, regeneration and state-led gentrification in London. Urban Policy and Research, 27(3): 229-242. DOI: http://dx.doi. org/10.1080/08111140903154147

Watt, P 2013 'It's not for us': Regeneration, the 2012 Olympics and the gentrification of East London. City, 17(1): 99-118. DOI: http://dx.doi.org/10.1080/13604813.2012.754190

Wrights \& Sites 2003 An Exeter Mis-Guide. Exeter: Wrights \& Site.

How to cite this article: Roberts, D 2014 Telling Stories / Empty Words Build Empty Homes. Opticon1826, (16): 17, pp.1-22, DOI: http://dx.doi.org/10.5334/opt.bq

Published: 15 October 2014

Copyright: (c) 2014 The Author(s). This is an open-access article distributed under the terms of the Creative Commons Attribution 3.0 Unported License (CC-BY 3.0), which permits unrestricted use, distribution, and reproduction in any medium, provided the original author and source are credited. See http://creativecommons.org/licenses/by/3.0/.

]u[ Opticon1826 is a peer-reviewed open access journal published by

]u[ Ubiquity Press 